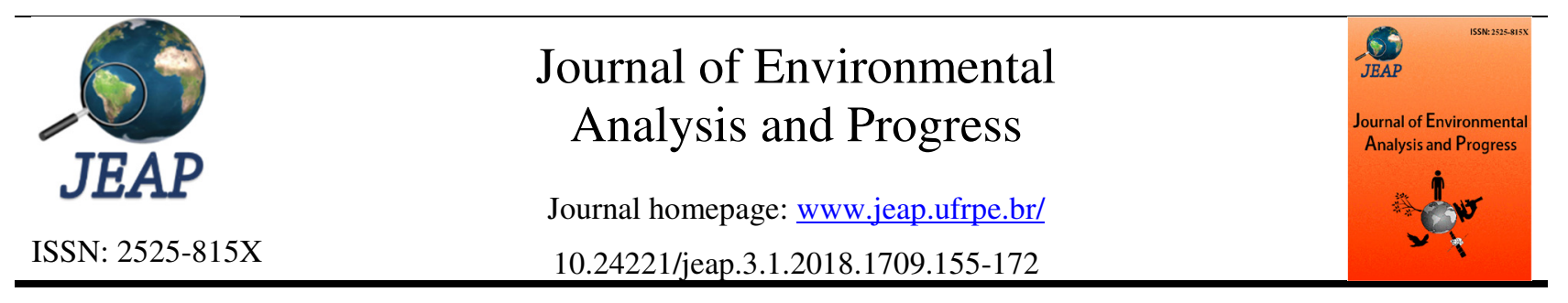

\title{
Modelagem hidrológica da Bacia Hidrográfica do Rio Pirapama-PE utilizando o modelo SWAT
}

\section{Hydrological modeling of the Pirapama River-PE Basin using the SWAT model}

Jussara Freire de Souza Viana ${ }^{a}$, Suzana Maria Gico Lima Montenegro ${ }^{a}$, Bernardo Barbosa da Silva $^{\mathrm{b}}$, Richarde Marques da Silva ${ }^{\mathrm{c}}$, Wanderson dos Santos Sousa ${ }^{\mathrm{d}}$

a Universidade Federal de Pernambuco-UFPE, Centro de Tecnologia e Geociências, Departamento de Engenharia Civil, Rua: Acadêmico Hélio Ramos, s/n, Recife-PE, Brasil. CEP: 50740-530. E-mail: jussarafsouza@yahoo.com.br, suzanam.ufpe@gmail.com.

b Universidade Federal de Campina Grande-UFCG, Centro de Tecnologia e Recursos Naturais, Rua Aprígio Veloso, n. 882, Campina Grande, Paraíba, Brasil. CEP: 58429-900.

${ }^{c}$ Universidade Federal da Paraíba-UFPB, Avenida Cidade Universitária, s/n, João Pessoa, Paraíba, Brasil. CEP: 58059900.

${ }^{\mathrm{d}}$ Instituto de Tecnologia de Pernambuco-ITEP, Avenida Professor Luiz Freire, n. 700, Recife, Pernambuco, Brasil. CEP: 50740545

\begin{tabular}{l}
\hline A R T I C L E I N F O \\
\hline Recebido 14 Nov 2017 \\
Aceito 31 Jan 2018 \\
Publicado 31 Jan 2018
\end{tabular}

\begin{abstract}
A B S T R A C T
Hydrological studies in watersheds are based on the need to understand the functioning of the water balance and the processes that control water movement, as well as the impacts of changes in land use on the quantity and quality of water. Research related to the understanding of hydrological processes through the use of rainfall-flow prediction models is of great importance for the management and planning of water resources. In this perspective, the objective of this study was to perform and analyze hydrological modeling using the SWAT model in the Pirapama river basin, in Pernambuco State, seeking results related to hydrological processes, considering the need for information for the basin, which is very important for water supply of Recife Metropolitan Region. Considering the initial hydrological modeling, meteorological data were used from 2000 to 2006, land use map obtained from two images of the Landsat 5-TM satellite (2005 and 2007), a 30m digital elevation map (USGS-NASA site) and the map of the soil types of the basin obtained through the ZAPE (Agroecological Zoning of Pernambuco). The mean annual rainfall of the basin was $1891.94 \mathrm{~mm}$, the average observed, and simulated discharges were $7.19 \mathrm{~m}^{3} \cdot \mathrm{s}^{-1}$ and $5.73 \mathrm{~m}^{3} \cdot \mathrm{s}^{-1}$, respectively. The model underestimated the simulated discharge when compared to the observed discharge, especially in the higher peaks of the flow, as in the middle of the years 2000, 2002, 2004 and 2006, where the underestimation was more significant. Future studies can be used to improve the simulation after performing the calibration and validation process of the model at the Pirapama river basin. After calibration and validation, the model can be used for predictive scenarios of impacts of climate change and changes in land use. Keywords: Water balance, distributed modeling, water resources modeling.
\end{abstract}

\section{R E S U M O}

Os estudos hidrológicos em bacias hidrográficas partem da necessidade de se entender o funcionamento do balanço hídrico e os processos que controlam o movimento da água, assim como os impactos das mudanças do uso do solo sobre a quantidade e qualidade da água. Pesquisas relacionadas ao entendimento dos processos hidrológicos por meio da utilização de modelos de predição chuva-vazão são de grande importância para a gestão e planejamento dos recursos hídricos. Nessa perspectiva, o objetivo desse estudo foi realizar e analisar a modelagem hidrológica por meio do modelo SWAT na Bacia Hidrográfica do Rio Pirapama-PE, buscando 
resultados relacionados aos processos hidrológicos, visto a necessidade de informações para a referida bacia, que tem extrema importância para o abastecimento da Região Metropolitana do Recife. Considerando a modelagem hidrológica inicial foram utilizados dados meteorológicos do período de 2000 a 2006, mapa de uso e ocupação do solo obtido a partir de duas imagens do satélite Landsat 5-TM (2005 e 2007), mapa digital de elevação de 30m (site da USGS-NASA) e o mapa dos tipos de solo da bacia obtido por meio do ZAPE (Zoneamento Agroecológico de Pernambuco). A precipitação média anual da bacia foi igual a 1891,94 mm, a média da vazão observada foi de $7,19 \mathrm{~m}^{3} \cdot \mathrm{s}^{-1}$ e a simulada $5,73 \mathrm{~m}^{3} \cdot \mathrm{s}^{-1}$. O modelo subestimou os dados de vazão quando comparado aos dados observados, sobretudo nos picos mais elevados da vazão, como em meados dos anos 2000, 2002, 2004 e 2006, onde a subestimativa foi mais significativa. Estudos futuros podem vir a melhorar a simulação após a aplicação do processo de calibração e validação do modelo na Bacia do Rio Pirapama. Após a calibração e validação o modelo pode ser usado para cenários de previsão de impactos de mudanças climáticas e de alterações de uso do solo.

Palavras-Chave: Balanço hídrico, modelagem distribuída, gestão de recursos hídricos.

\section{Introdução}

Os estudos hidrológicos em bacias hidrográficas partem da necessidade de se entender o funcionamento do balanço hídrico e os processos que controlam o movimento da água, assim como os impactos das mudanças do uso do solo sobre a quantidade e qualidade da água. Sendo assim, temse a bacia hidrográfica como uma unidade hidrológica de estudo e também como unidade de planejamento, devido suas características estarem diretamente ligadas à produção de água (Rennó \& Soares, 2003).

A água é um dos recursos fundamentais para a vida, cuja importância é primordial para a pecuária, alimentação humana e animal, para a navegação, lazer, geração de energia e outras atividades ligadas diretamente à vida no planeta. Atualmente a água está no centro das atenções mundiais, seja pelos índices de qualidade ou pela quantidade de demanda (Borges, 2013).

De acordo com Silva (2014), nas últimas décadas tem se observado um aumento da degradação do solo e uma diminuição na disponibilidade hídrica em várias áreas do Brasil e do mundo. No Brasil, embora exista uma disponibilidade hídrica significativa, sua distribuição é considerada irregular, tanto no tempo quanto no espaço. Diante disso, identifica-se dois desafios a serem enfrentados no país: o primeiro diz respeito à escassez de água em algumas regiões, como é o caso da porção semiárida da região Nordeste, e o outro se refere à reduzida qualidade das águas (Batista et al., 2013).

No Brasil, os problemas oriundos da escassez de água estão ligados, principalmente, à prática da irrigação, ou seja, a prática que mais demanda por água, em torno de $70 \%$ (Setti et al., 2001).

Neste contexto, as bacias hidrográficas possuem grande importância e relevância para o suprimento hídrico de regiões, pois propiciam diferentes formas de uso e ocupação, no qual incluem áreas de cultivo, áreas urbanas, atividades industriais e agropecuárias, áreas com preservação da vegetação nativa, entre outras.

Dessa forma, os estudos e investigações científicas voltadas para o entendimento dos processos hidrológicos em bacias hidrográficas permitem auxiliar na preservação dos recursos hídricos e, consequentemente, no desenvolvimento das regiões. Sendo assim, entende-se que modelos hidrológicos que representem de forma consistente os processos hidrológicos que ocorrem em bacias hidrográficas podem de fato contribuir para o planejamento e gestão dos recursos hídricos (Santos et al., 2013).

A modelagem é uma ferramenta importante de apoio à gestão e à tomada de decisões sobre o uso do solo e da água. Os modelos são capazes de representar os processos físicos de um sistema, e de gerar informações normalmente não disponíveis (Andrade et al., 2016). A importância de um modelo hidrológico está na sua capacidade de resumir informações hidrológicas importantes para tomada de decisão, dentro da finalidade do gerenciamento e planejamento de recursos hídricos (Klemes, 1986).

A modelagem hidrológica permite verificar a consistência das informações disponíveis (dados observados), que são em geral muito curtas, obtidas a partir das observações hidrológicas nas bacias hidrográficas, e com base nesses dados, os modelos hidrológicos podem ser calibrados, permitindo, por exemplo, a geração de séries simuladas e a utilização dos modelos como ferramenta de obtenção de dados em bacias não monitoradas (Santos, 2009).

A utilização de modelos hidrológicos proporciona custos menores e economia de tempo para analisar mudanças físicas e antrópicas na 
bacia, que em geral, em uma bacia experimental, levaria muito tempo e pessoas capacitadas para analisar os fenômenos hidrológicos (Nóbrega et al., 2008). Para avaliar os processos hidrológicos que ocorrem dentro da bacia é necessário monitora-los no tempo e no espaço, por meio de estações pluviométricas, fluviométricas, meteorológicas e sedimentológicas instaladas em diferentes locais na bacia hidrográfica. Porém, esse monitoramento, muitas vezes torna-se inviável pelo seu alto custo, e nem sempre abrange todas as partes da bacia.

Por essa razão, muitos modelos hidrológicos têm sido desenvolvidos desde bases conceituais mais simples até mais complexas com o desenvolvimento da computação e inserção dos SIGs, que originou os modelos distribuídos de base física. Esses modelos conseguem simular os processos hidrológicos de forma distribuída na bacia hidrográfica, permitindo estimar, com certa confiabilidade, a produção de água e sedimentos, como, por exemplo, o Soil and Water Assessment Tool (SWAT) (Colombo et al., 2016).

O SWAT permite representar distintos processos físicos em uma bacia hidrográfica como, a evapotranspiração, infiltração, escoamento de água, entre outros, com o objetivo de analisar os impactos gerados por alterações no uso do solo sobre o escoamento (superficial e subterrâneo), produção de sedimentos e também qualidade de água, de forma espacializada em bacias hidrográficas grandes e complexas, não instrumentadas (Neitsch et al., 2011). Esse modelo se destaca pela sua robustez, capacidade de análise e correlação que obtém entre elementos físicos de uma bacia hidrográfica. Pesquisadores do mundo todo têm aplicado esse modelo com resultados satisfatórios (Srinivasan et al., 2009; Al-Dousari et al., 2010; Arnold et al., 2012; Santos et al., 2013; Pagliero et al., 2014; Sousa et al., 2015; Bressiani et al., 2015).

Nessa perspectiva, o objetivo do estudo foi realizar e analisar a modelagem hidrológica por meio do modelo SWAT na Bacia Hidrográfica do Rio Pirapama-PE, buscando resultados relacionados aos processos hidrológicos, visto a necessidade de gerar informações que possam subsidiar a gestão dos recursos hídricos dessa bacia, considerada de grande importância para a região metropolitana do Recife.

\section{Material e Métodos}

\section{Área de estudo}

O estudo foi desenvolvido na Bacia do Rio Pirapama, situada na porção centro-sul da Região Metropolitana do Recife (RMR) e na Zona da Mata Pernambucana, mais precisamente entre as latitudes $8^{\circ} 07^{\prime} 29^{\prime \prime}$ e $8^{\circ} 21^{\prime} 00^{\prime \prime} \mathrm{S}$ e longitudes $34^{\circ}$ 56 '20" e $35^{\circ} 23^{\prime} 13^{\prime \prime}$ W. Essa bacia possui uma área de aproximadamente $600 \mathrm{~km}^{2}$ com extensão de 80 $\mathrm{km}$, cuja nascente localiza-se no município de Pombos, no Agreste de Pernambuco, a $450 \mathrm{~m}$ de altitude. Sua desembocadura localiza-se no rio Jaboatão, entre os municípios de Cabo de Santo Agostinho e Jaboatão dos Guararapes, considerado ponto estratégico para o abastecimento da RMR (CPRH, 1998). Conforme o Plano Estadual de Recursos Hídricos (SECTMA, 1998), a bacia hidrográfica do Rio Pirapama compõe a Unidade de Planejamento Hídrica, denominada UP15, do grupo de bacia GL2, grupo de Pequenas Bacias Litorâneas (Figura 1).
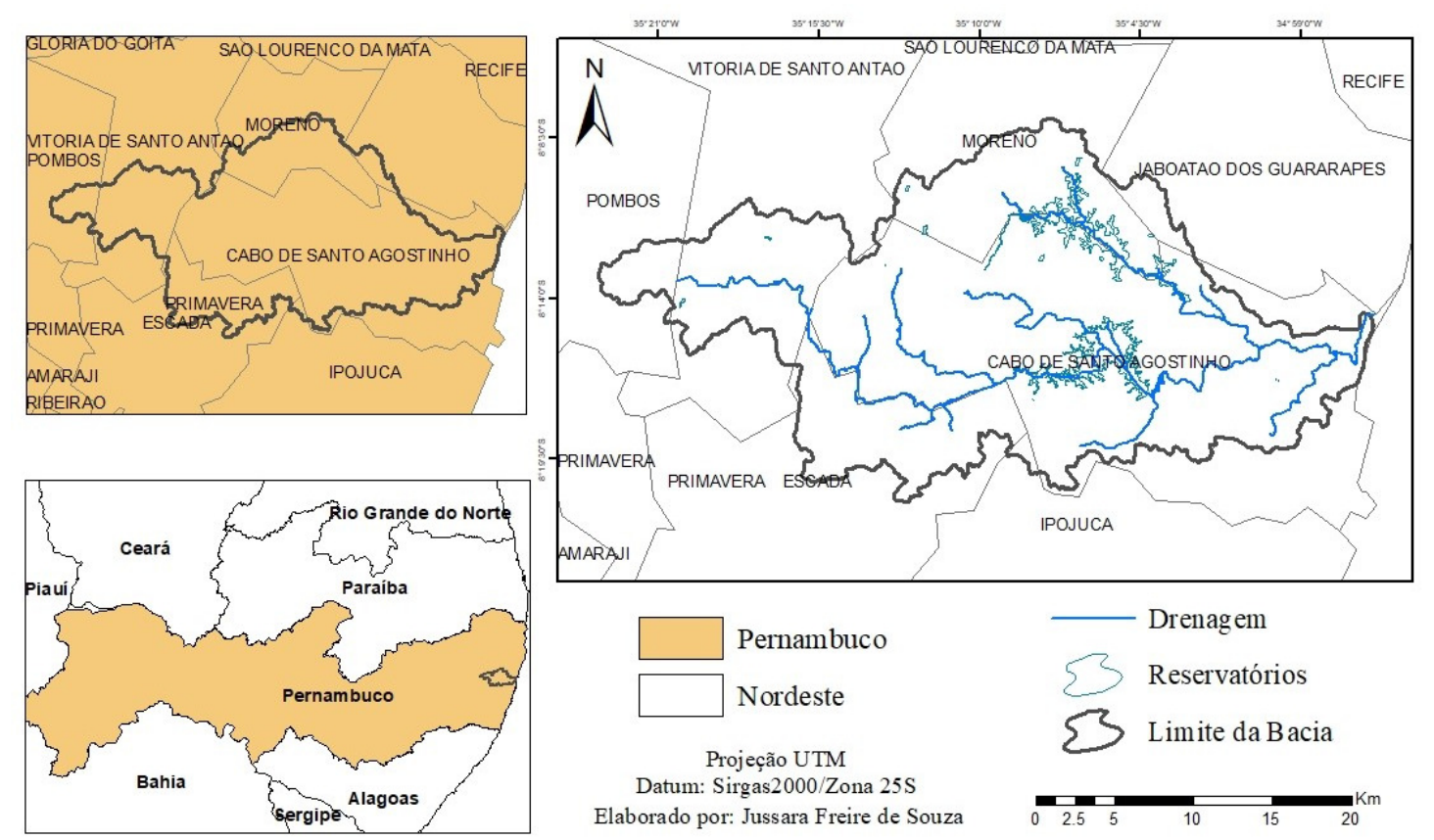

Figura 1. Localização da Bacia Hidrográfica do Rio Pirapama, no Estado de Pernambuco. 
A referida bacia limita-se ao norte com as bacias dos Rios Jaboatão e Tapacurá (afluente do Capibaribe), ao sul com as bacias dos Rios Ipojuca e Massangana, a oeste com a bacia do Rio Ipojuca e a leste com o oceano Atlântico. Sua rede hidrográfica tem como principais tributários da margem esquerda os rios Gurjaú, Cajabuçu e Arariba e os riachos dos Macacos e Arandu. Na margem direita, destacam-se os riachos Santa Amélia, Utinga de Cima e Camaçari (Falcão Neto, 2002).

A bacia do Pirapama abrange a área de sete municípios: Cabo de Santo Agostinho, Jaboatão dos Guararapes, Ipojuca e Moreno, inseridos na RMR; Vitória de Santo Antão, Escada e Pombos localizados na Zona da Mata Pernambucana. A maior proporção da área da bacia encontra-se situada no território do município do Cabo de Santo Agostinho (57,2\%), seguido por Moreno (13,7\%), Escada (11,8\%), Vitória de Santo Antão (9,5\%), Pombos $(4,3 \%)$ e Jaboatão dos Guararapes $(2,4 \%)$ (Figura 1). O município de Ipojuca ocupa apenas $1,1 \%$ da área da bacia (Silva \& Santos, 2005). Em conjunto, os municípios integrantes da bacia totalizam cerca de 1.158.595 habitantes, dos quais, $84,4 \%$ residem em áreas urbanas (IBGE, 2010).

Grande parte da bacia é ocupada por atividades agrícolas, mas também existe a presença significativa da atividade industrial, além da geração de energia elétrica por pequenas centrais hidrelétricas. A demanda principal de água na bacia é a de abastecimento humano, que atende a demanda local e é parcialmente exportada para atender parte da RMR. De acordo com a CPRH (2004), a atividade industrial é um importante segmento produtivo da área com 24 indústrias estabelecidas, voltadas para as seguintes áreas: químico, sucroalcooleira, bebidas, minerais não metálicos, mecânica, produtos alimentares, têxtil, matéria plástica e borracha.

O clima da região é do tipo As' (pseudo tropical), quente e úmido, segundo a classificação climática de Köppen, com abrandamento da forte radiação solar, pelos ventos alísios. A média mensal de temperatura varia entre $26^{\circ} \mathrm{C}$ e $28^{\circ} \mathrm{C}$, enquanto a umidade relativa do ar é superior a $70 \%$ durante os meses de março a setembro (CPHR, 2003). Quanto ao regime de chuvas, a região possui dois períodos bem definidos: seco, entre os meses de setembro a fevereiro, com precipitação média mensal menor do que $60 \mathrm{~mm}$ e evaporação que excede a precipitação; e chuvoso, entre os meses de março a agosto, no qual o balanço hidrológico geralmente é positivo. As médias anuais da precipitação e da evaporação na região ficam em torno de $1500 \mathrm{~mm}$ e $1200 \mathrm{~mm}$, respectivamente (Stretta, 2000).
O relevo é típico do modelado cristalino e apresenta morros e colinas arredondados com altitudes superiores a $60 \mathrm{~m}$, com vales encaixados e ativos (Gomes, 2004). A descrição da geologia do relevo da Bacia está baseada nas características morfológicas do coletor principal, subdividido em três trechos, o alto curso, o médio curso e o baixo curso.

Em relação à pedologia da Bacia do Rio Pirapama, de acordo com Gama (2001), os solos predominantes na área são os argissolos, latossolos e os gleissolos. Em menor escala, ocorrem na bacia a associação de solos espodossolos, neossolos quartzarênico (na baixada paralela à orla marinha) e solos de mangue (EMBRAPA, 2002).

O uso e ocupação do solo da Bacia do Rio Pirapama é bastante diversificado, caracterizado pela ocupação urbana e industrial, fazendas e granjas, policultura (assentamentos rurais), e duas pequenas hidrelétricas, áreas de cultivo de cana-deaçúcar, mata atlântica e manguezais (Silva \& Santos, 2005).

\section{Modelo Soil and Water Assessment Tools (SWAT) \\ O modelo SWAT foi desenvolvido pelo} Agricultural Research Service/United States Department of Agriculture (ARS/USDA) dos Estados Unidos. Ele permite a modelagem hidrológica de bacias hidrográficas e a análise de diversos cenários, como a predição dos impactos: do manejo do solo sobre a qualidade da água, do transporte de sedimentos, e do transporte de químicos agrícolas. O SWAT possibilita a modelagem de grandes bacias hidrográficas, com diferentes tipos e usos do solo ao longo de grandes intervalos de tempo (Neitsch et al., 2005). É um modelo distribuído de base física, continuo no tempo, o qual simula o escoamento superficial, a erosão em planos e canais, o transporte de nutrientes e pesticidas em escalas de tempo diárias, mensais e anuais (Aragão et al., 2013; Neitsch et al., 2011). O modelo hidrológico é baseado na equação do balanço hídrico, tendo como volume de controle um perfil de solo de $2 \mathrm{~m}$ de profundidade (Arnold et al., 1998) (Equação 1):

$$
\mathrm{SW}_{\mathrm{t}}=\mathrm{SW}_{0}+\sum_{\mathrm{i}=1}^{\mathrm{t}}\left(\mathrm{R}_{\mathrm{d}}-Q_{\text {sup }}-\mathrm{E}_{\mathrm{a}}-\mathrm{W}_{\text {seep }}-Q_{\mathrm{gw}}\right)
$$

onde $\mathrm{SW}_{\mathrm{t}}$ é o armazenamento final da água no solo $(\mathrm{mm}) ; \mathrm{SW}_{0}$ é o armazenamento inicial da água no solo no dia i (mm); t é o tempo (dias); $\mathrm{R}_{\mathrm{d}}$ é a precipitação no dia i (mm); $\mathrm{Q}_{\text {sup é o escoamento }}$ superficial no dia i (mm); $E_{a}$ é a evapotranspiração no dia i (mm); $W_{\text {seep }}$ é a percolação no dia i $(\mathrm{mm})$; $\mathrm{Q}_{\mathrm{gw}}$ é o fluxo de retorno (ascensão capilar a partir da zona vadosa) no dia i (mm). 
O escoamento superficial é estimado a partir de dois métodos: Curva Número (SCS - Soil Conservation Service) e o método de infiltração de Green Ampt (Neitsch et al., 2011). Neste estudo, o escoamento superficial é calculado usando o método número da Curva Número SCS modificado (NEITSCH al., 2011).

$$
Q_{\text {sup }}=\frac{\left(R_{d}-I_{a}\right)^{2}}{\left(R_{d}-I_{a}+S\right)}
$$

onde $\mathrm{Q}_{\text {sup }}$ é o escoamento superficial acumulado ou o excesso de precipitação $\left(\mathrm{mm} \mathrm{H}_{2} \mathrm{O}\right), \mathrm{R}_{\mathrm{d}}$ é a lamina precipitada para o dia $(\mathrm{mm}), \mathrm{I}_{\mathrm{a}}$ é a abstração inicial a qual inclui o armazenamento superficial, a interceptação e a infiltração inicial para o escoamento $(\mathrm{mm})$, e $\mathrm{S}$ é o parâmetro de retenção $(\mathrm{mm})$. O parâmetro de retenção varia espacialmente devido à mudança no solo, uso da terra, manejo e declividade e temporalmente devido às mudanças do conteúdo de água do solo. O parâmetro de retenção é definido por:

$$
Q_{\text {sup }}=\frac{\left(R_{d}-0,2 S\right)^{2}}{\left(R_{d}+0,8 S\right)}
$$

onde CN é a Curva Número. A abstração inicial, $\mathrm{I}_{\mathrm{a}}$, é comumente aproximado de 0,2S e na Equação 2 tem-se:

$$
\mathrm{S}=25,4\left(\frac{1000}{\mathrm{CN}}-10\right)
$$

No início da modelagem hidrológica com o SWAT, a bacia hidrográfica é dividida em subbacias e a quantidade destas depende da área mínima de drenagem. Com a delimitação finalizada, o modelo faz combinações entre o uso e ocupação do solo, tipos de solos e declividade, que origina as Unidades de Resposta Hidrológica (HRUs). Os processos hidrológicos que podem ser simulados no SWAT são: interceptação, infiltração, redistribuição da água, evapotranspiração

\section{Dados de entrada do modelo SWAT}

Para obter a modelagem inicial da bacia, o SWAT necessita de três diferentes arquivos geoespaciais, no qual é composto pelo modelo digital de elevação (MDE), mapa de tipos de solo da área de estudo e o mapa de uso e ocupação do solo. Além desses dados são necessários dados tabulares referentes às condições climáticas da região de estudo, sendo eles caracterizados por informações de precipitação, temperatura máxima e mínima, radiação solar, velocidade do vento e umidade relativa.

Por meio da interface ArcSWAT, os dados geoespaciais são tratados e convertidos em informações para o processo de funcionamento do modelo. Após o tratamento e organização dos dados é possível estabelecer parâmetros adequados para utilizar no modelo, almejando resultados mais consistentes possíveis. Nos itens a seguir serão apresentados os dados de entrada que foram utilizados para realizar a modelagem pelo SWAT na Bacia Hidrográfica do Rio Pirapama.

\section{Modelo Digital de Elevação (MDE)}

Para a aplicação do processo inicial da modelagem hidrológica na Bacia do Rio Pirapama, realizou-se a delimitação automatizada da bacia utilizando o Modelo Digital de Elevação (MDE) da área de estudo, por meio do ArcSWAT (Figura 2).

No entanto, antes da utilização do MDE pelo ArcSWAT, realizaram-se alguns procedimentos na ferramenta do ArcGis, Archydro, para o preenchimento de falhas na carta imagem do MDE, proveniente do processo de aquisição dos dados obtidos por sensoriamento remoto. Após esse processo, realizou-se o recorte retangular do MDE para acelerar a delimitação.

O MDE utilizado possui resolução espacial de $30 \mathrm{~m}$ (nativo) e foi obtido pelo site da States Geological Survey (USGS), no seguinte endereço eletrônico: http://earthexplorer.usgs.gov/. Esse MDE é originário da Shuttle Radar Topography Mission (SRTM), que é liderada pela Agência Nacional de Inteligência Geoespacial e pela NASA dos Estados Unidos, desde o ano de 2000.

No processo de delimitação automatizada da bacia, o ArcSWAT gera a rede de drenagem da área e divide a bacia em sub-bacias de acordo com o relevo apresentado pelo MDE. O modelo digital de elevação também é utilizado para o cálculo de parâmetros de área, declividade média e elevação (média, máxima e mínima) para cada sub-bacia. 


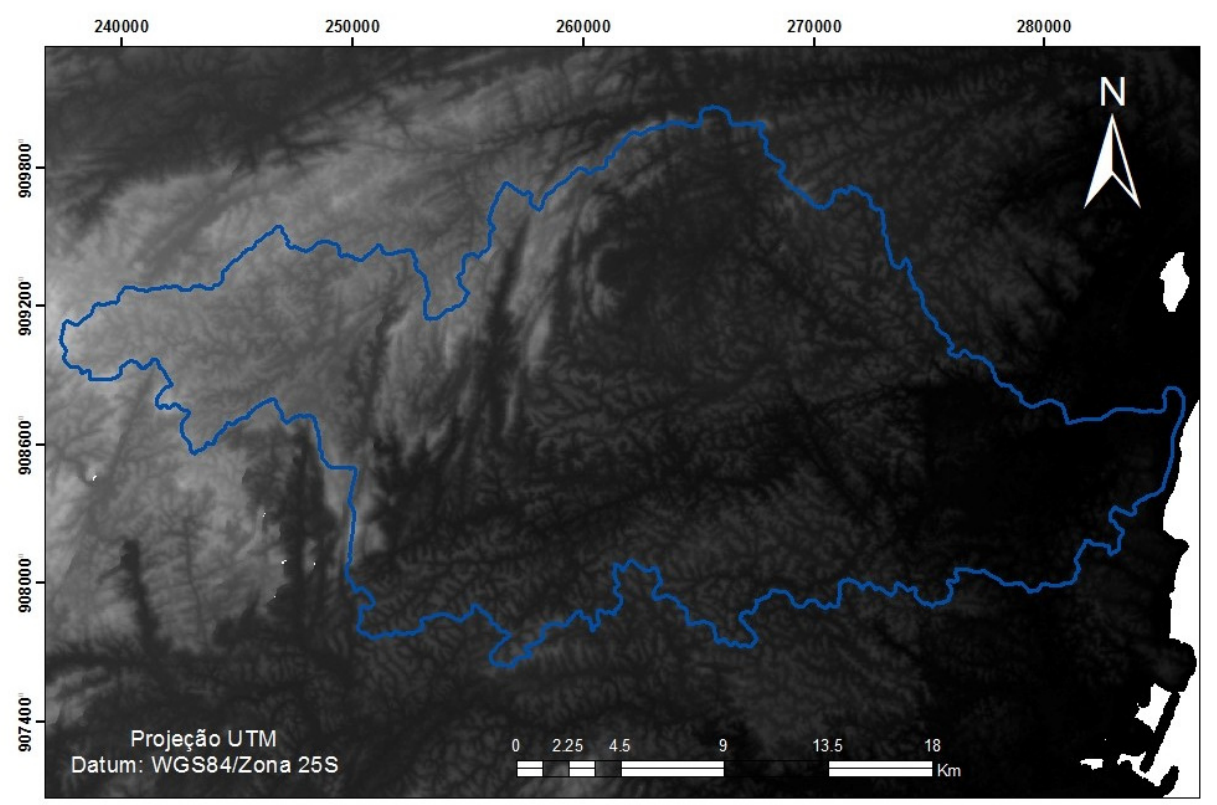

Figura 2. Modelo Digital de Elevação (MDE) utilizado para delimitação automatizada da Bacia do Rio Pirapama. Fonte: USGS (2016).

Mapa de uso e ocupação do solo e tipos de solo

O mapa de uso e ocupação do solo utilizado neste estudo foi elaborado a partir de duas imagens de satélite do Landsat 5, com resolução espacial de $30 \mathrm{~m}$ (sensor TM; órbita 214; ponto 066), obtidas junto ao Instituto Nacional de Pesquisas Espaciais (INPE). As imagens correspondem ao dia 06 de julho de 2005 e 28 de julho de 2007, sendo as únicas que apresentaram menor quantidade de nuvens na região. Por não haver imagem sem a presença de nuvens na área de estudo e não haver classificação do uso do solo espacializada em bibliografias referentes à área da bacia fez-se necessário a montagem de uma imagem de satélite sem a presença de nuvens, por meio do recorte das áreas onde não havia nuvens nas duas imagens do Landsat 5 - TM utilizadas.

Após o recorte das áreas sem nuvens nas imagens de 2005 e 2007, aplicou-se o mosaico em um ponto comum entre as duas imagens. Dessa forma, transformou-se duas imagens de períodos distintos em uma única imagem de satélite, tornando possível a confecção do mapa de uso e ocupação do solo para aplicação no SWAT (Figura 3). Entretanto, por causa da má qualidade da imagem gerada por esta composição, não foi possível obter um nível maior de detalhe quanto à classificação do uso e ocupação do solo da Bacia do Rio Pirapama.

No processo de classificação do uso e ocupação do solo da Bacia, definiu-se as classes de usos do solo de maior evidência na região, utilizando a classificação supervisionada do software Arcgis $10.2^{\circledR}$, onde determinou-se seis classes de uso e ocupação do solo, sendo elas: água, área urbana, solo exposto, vegetação densa, vegetação rasteira e cana-de-açúcar. Depois de concluído o processo de classificação e a composição do mapa, os usos do solo existentes na bacia foram associados aos usos do solo correspondentes ao banco de dados do modelo SWAT após a introdução desse plano de informação no ArcSWAT. A Tabela 1 apresenta a associação dos usos do solo presentes na bacia com os usos do banco de dados do modelo SWAT.

Tabela 1. Associação dos usos do solo do SWAT com os usos presentes na Bacia do Rio Pirapama.

\begin{tabular}{llll}
\hline Uso e ocupação do solo & Usos do solo no SWAT & Área $\left(\mathbf{k m}^{2}\right)$ & Área $(\%)$ \\
\hline Água & Water (WATR) & 7,86 & 1,31 \\
Cana-de-açúcar & Sugarcane (SUGC) & 277,19 & 46,20 \\
Vegetação rasteira & Pasture (PAST) & 173,03 & 28,83 \\
Solo Exposto & Barren (BARR) & 67,61 & 11,27 \\
Área urbana & Urban (URBN) & 10,62 & 1,77 \\
Vegetação densa & Forest-Mixed (FRST) & 63,61 & 10,60 \\
\hline
\end{tabular}


O Swat requer uma série de dados das características físico-hídricas dos solos para poder realizar as simulações hidrológicas. Os parâmetros de solo necessários à simulação são os grupos hidrológicos ao qual o solo pertence (HYDGRP), profundidade da camada (SOL_Z - mm) e da raiz (SOL_ZMX - mm.h ${ }^{-1}$ ), percentagem de argila (SOL_CLAY- \%), silte (SOL_SILT - \%), areia
(SOL_SAND - \%), cascalho (SOL_ROCK - \%) e carbono orgânico (SOL_CBN - \%), densidade

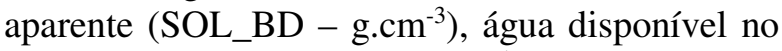
solo (SOL_AWC $-\mathrm{mm} \cdot \mathrm{mm}^{-1}$ ), condutividade hidráulica saturada (SOL_K $\left.-\mathrm{mm} \cdot \mathrm{h}^{-1}\right)$, erodibilidade (USLE_K) e albedo (SOL_ALB fração) (Neitsch et al., 2005).

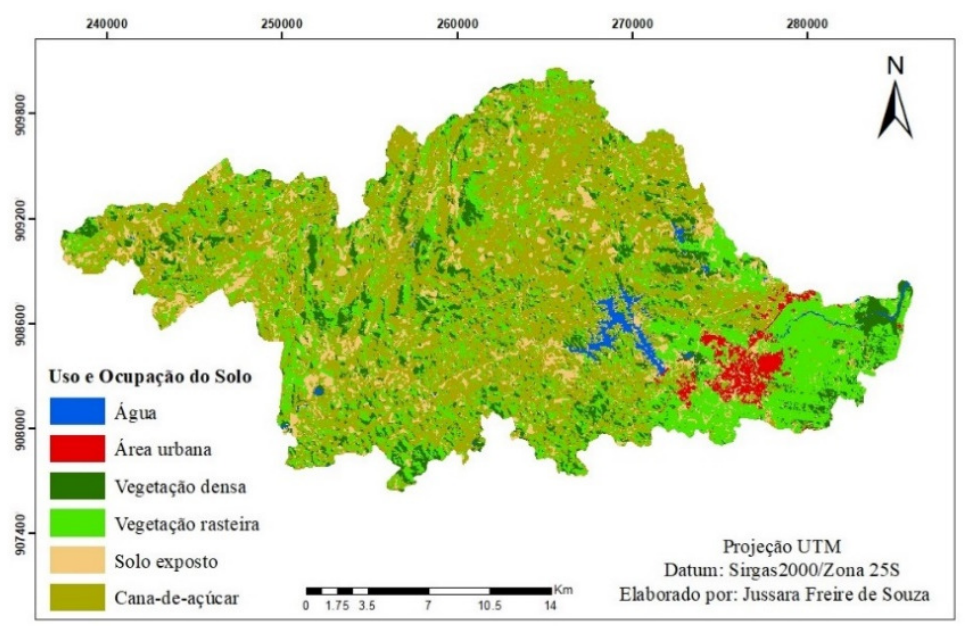

Figura 3. Uso e ocupação do solo da Bacia do Rio Pirapama.

Os parâmetros do solo obtidos para a região da bacia estudada seguiram as classificações da EMBRAPA Solos por meio do portal na internet: Sistema de Informação de Solos Brasileiros

(http://www.sisolos.cnptia.embrapa.br/) e dos estudos aplicados no Brasil que definiram valores para alguns parâmetros do solo (Mercuri et al., 2009; Fernandes, 2015; Lelis et al., 2012; Santos et al., 2015; Gomes, 2002; IBGE, 2007; Baldissera, 2005). As informações de solo da área de estudo foram inseridas diretamente no banco de dados do modelo.

O mapa de tipos de solos (Figura 4) foi obtido a partir de dados fornecidos pela EMBRAPA Solos, com base nas informações fornecidas pelo Zoneamento Agroecológico de Pernambuco (ZAPE), cuja escala é de 1:100000. Esse mapa foi utilizado como um dos dados de entrada para a modelagem da bacia no SWAT, com o intuito de criar as URHs - Unidades de Respostas Hidrológicas. A Tabela 2 mostra a área ocupada por cada tipo de solo na Bacia.

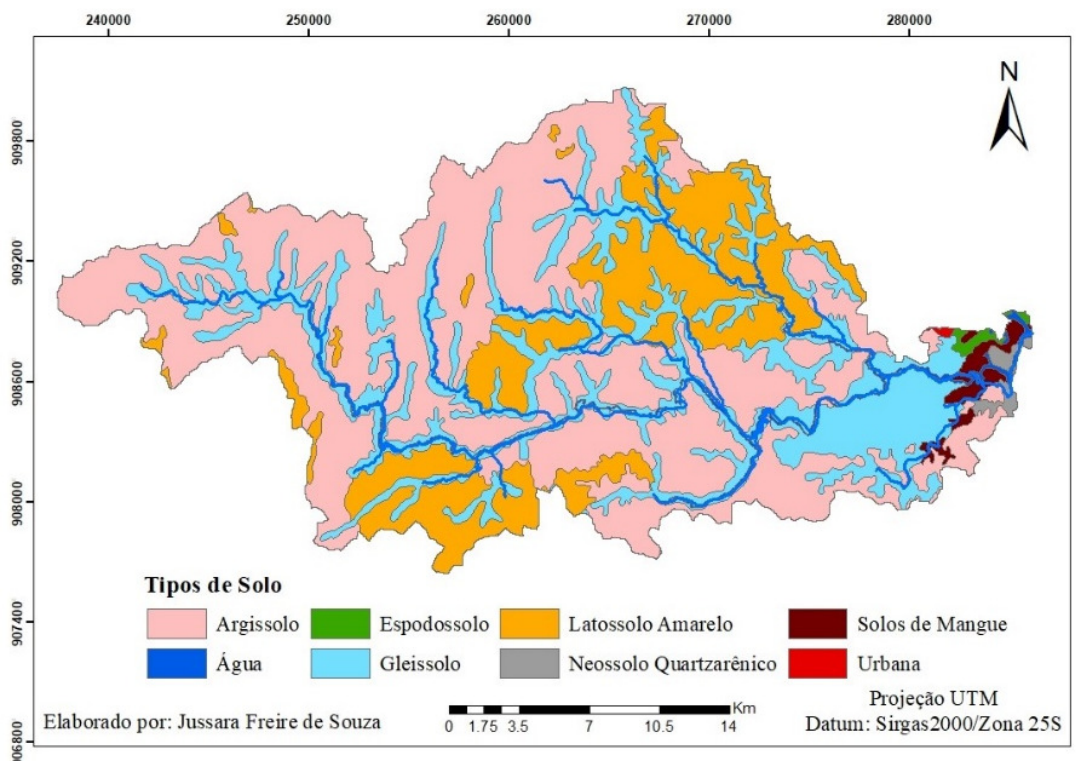

Figura 4. Tipos de solo da Bacia do Rio Pirapama. Fonte: Adaptado de Embrapa - ZAPE (2002). 
Tabela 2. Área ocupada por cada tipo de solo presente na Bacia do Rio Pirapama.

\begin{tabular}{lll}
\hline Tipos de Solo & Área $\left(\mathbf{k m}^{\mathbf{2}}\right)$ & Área $\mathbf{( \% )}$ \\
\hline Água & 8,03 & 1,34 \\
Neoossolo Quartzarênico & 3,28 & 0,55 \\
Gleissolo & 153,42 & 25,57 \\
Espodossolo & 1,86 & 0,31 \\
Latossolo Amarelo & 118,50 & 19,75 \\
Argissolo & 307,42 & 51,23 \\
Solos de Mangue & 7,10 & 1,18 \\
Área Urbana & 0,39 & 0,07 \\
\hline
\end{tabular}

\section{Dados meteorológicos e fluviométricos}

Para a modelagem hidrológica da Bacia do Rio Pirapama pelo modelo SWAT utilizou-se dados diários de precipitação de três postos pluviométricos e de três estações meteorológicas. Os dados diários das variáveis meteorológicas utilizadas para a modelagem hidrológica no SWAT foram obtidos a partir de dois pontos de grade globais que se encontram nas proximidades da bacia, cujos dados são disponibilizados pelo site do
Global Weather Data for SWAT (https://globalweather.tamu.edu/). Foi utilizado também um posto fluviométrico da Agência Nacional de Águas (ANA) para analisar e comparar o resultado da vazão simulada (modelagem inicial sem calibração) com a observada. A Tabela 3 apresenta as informações dos postos pluviométricos, fluviométrico e das estações meteorológicas que foram utilizados neste estudo.

Tabela 3. Características dos postos pluviométricos, fluviométrico e das estações meteorológicas utilizados no estudo. $* \mathrm{NCEP}=$ National Centers for Environmental Prediction .

\begin{tabular}{lccccc}
\hline Código & Nome & Tipo & Responsável & Latitude & Longitude \\
\hline 39220000 & Destilaria Bom Jesus & Fluviométrica & ANA & $-8,15$ & $-35,04$ \\
83350 & Globais & Meteorológica & NCEP* & $-8,27$ & $-35,00$ \\
83353 & Globais & Meteorológica & NCEP* & $-8,27$ & $-35,31$ \\
82900 & Recife-Curado & Meteorológica & INMET & $-8,05$ & $-34,95$ \\
835138 & Pirapama & Pluviométrica & ANA & $-8,16$ & $-35,03$ \\
835068 & Vitória de Sto. Antão & Pluviométrica & ANA & $-8,64$ & $-35,17$ \\
835137 & Pombos & Pluviométrica & ANA & $-8,08$ & $-35,23$ \\
\hline
\end{tabular}

A comparação sem a calibração norteia os primeiros resultados simulados pelo SWAT com as informações adquiridas no momento. $\mathrm{O}$ posto fluviométrico utilizado para este estudo foi escolhido por apresentar dados observados de vazão com um período relevante para a pesquisa, e que não apresenta falhas no período adotado, uma vez que nas datas anteriores ao período selecionado há presença de falhas. Dessa forma, foram selecionados os dados observados de vazão que correspondem aos anos de 2000 a 2013, no entanto para a simulação inicial e composição desta pesquisa foi adotado o período de 2000 a 2006.

Para a seleção dos postos pluviométricos foram consideradas as séries históricas que correspondessem ao mesmo período dos dados fluviométricos e meteorológicos, e que apresentassem o menor número de falhas durante $\mathrm{o}$ período adotado para o estudo (2000 - 2006). Para o processamento do modelo, as falhas foram preenchidas com -99, conforme recomendações técnicas do modelo apresentadas no referencial teórico de entrada de dados, publicado por Arnold et al. (2012). Os dados foram devidamente organizados em formatos de tabela requeridos pelo SWAT. Para o preenchimento automático de falhas o SWAT utiliza o gerador climático WXGEN (Sharpley \& Williams, 1990), que tem como referência os dados mensais de estações climáticas.

A Figura 5 apresenta a espacialização das estações utilizadas neste estudo. Três estações meteorológicas foram utilizadas para aquisição dos parâmetros climáticos necessários à execução do modelo, no entanto para alimentar o gerador climático (WXGEN) utilizou-se apenas as duas estações Globais (Figura 5). A estação climatológica Recife-Curado (INMET) não foi utilizada para alimentar o gerador climático, por causa da constância de erros ao inserir os dados desta estação no banco de dados do SWAT. Dessa forma, optou-se por não utilizar esses dados para alimentar o gerador climático (WXGEN) nesta pesquisa. 


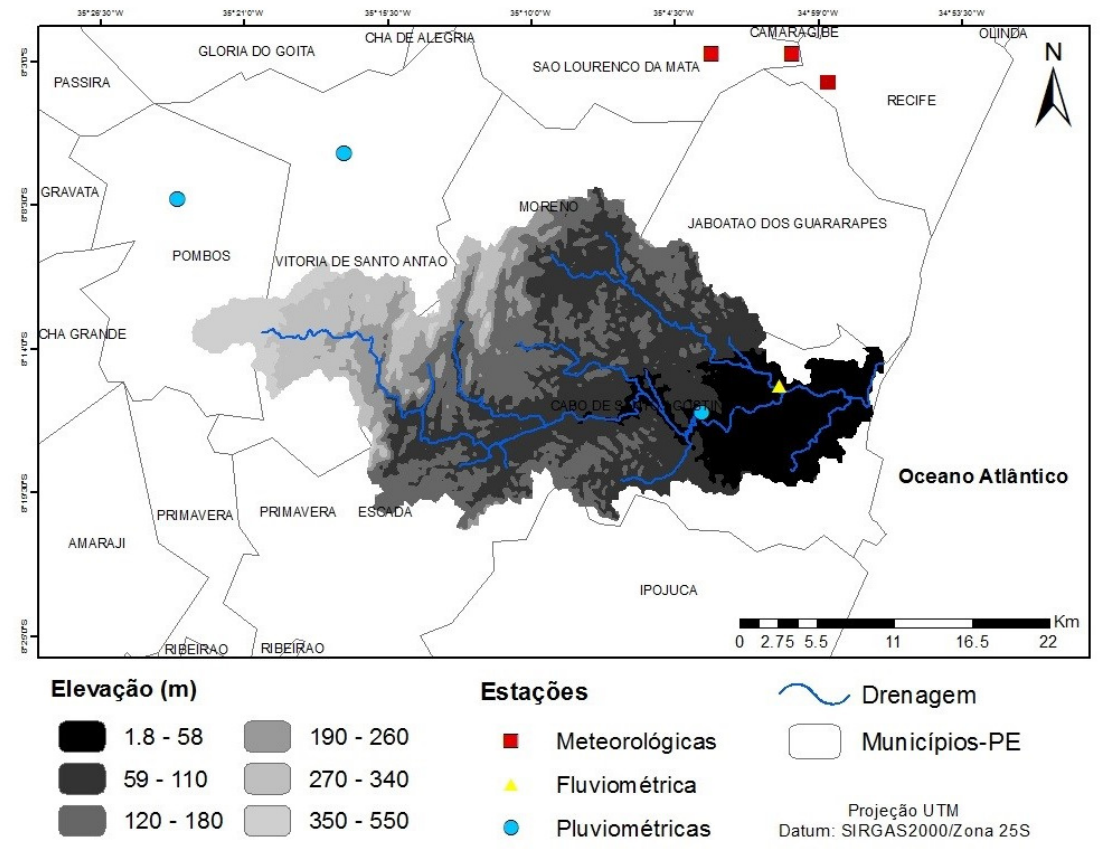

Figura 5. Localização das estações presentes na área da Bacia do Rio Pirapama.

\section{Análise de consistência}

A fim de verificar a consistência dos dados de precipitação, foi realizada uma análise de consistência dos dados para todas as estações utilizadas, por meio do método da Dupla Massa. Este é um método simples, desenvolvido pelo U.S. Geological Survey (Tucci \& Beltrame, 2014), que consiste em traçar em um gráfico os totais acumulados de precipitação do posto a consistir (posto cuja consistência se quer analisar) versus os totais acumulados de um posto base de comparação. Se os pontos do gráfico se alinharem em uma reta aproximada, indica uma proporcionalidade entre os dados dos postos em questão (Paz, 2004).

Com base nessas informações e no tratamento dos dados foram selecionados três postos pluviométricos, no qual um deles localizase dentro da bacia e dois no entorno dela. Além disso, para obter resultados mais consistentes ainda foram utilizados dados de precipitação das três estações meteorológicas próximas a área da bacia (Tabela 3).

\section{Etapas de Execução do modelo SWAT}

Para iniciar o processo de modelagem de uma bacia hidrográfica pelo SWAT é necessário criar um projeto na extensão ArcSWAT, onde serão armazenados todos os processos gerados e criados pelo modelo. Após esse primeiro passo, é inserido no modelo o MDE da área de estudo, necessário para delimitação e discretização da bacia. Esse processo fornece informações de altimetria, define a rede de drenagem da área e realiza a divisão da bacia em sub-bacias, calculando também parâmetros para cada subbacia.

A delimitação da Bacia do Rio Pirapama, assim como das suas sub-bacias foi realizada utilizando o recorte retangular do MDE citado anteriormente e o arquivo shapefile do rio principal da bacia (Rio Pirapama). A utilização do arquivo shapefile referente ao rio principal da bacia foi necessário devido à imprecisão do modelo em discretizar áreas cuja altitude é zero, ou seja, na área leste da bacia, onde encontra-se o seu exutório, o SWAT não representava bem a rede de drenagem, delimitando a bacia de forma diferente da realidade. Então, a partir da introdução da informação do rio principal obteve-se a delimitação e a discretização da bacia desejada.

$\mathrm{Na}$ sequência, definiu-se o exutório da bacia e após esse processo a delimitação das subbacias e o cálculo dos parâmetros físicos de cada uma delas. Na execução desse processo foram geradas 29 sub-bacias. A delimitação automática via interface ArcSWAT, apresentou um delineamento próximo ao estabelecido pelo Projeto de Planejamento e Gerenciamento da Bacia do Pirapama, conduzido pela CPRH (CPRH/DFID, 1998).

Após a discretização da bacia é inicializado o processo para definição das Unidades de Respostas Hidrológicas (URHs), onde são inseridos os mapas de uso e ocupação do solo, tipos de solo (Figura 3 e 4) e os intervalos de declividade da área de estudo (menu HRU Analysis do ArcSWAT). Os mapas depois de inseridos são associados às informações existentes no banco de dados, que pode ser incorporado pelo usuário ou original do SWAT. 
Seguindo a recomendação da Embrapa (2000) para a área de estudo, definiram-se cinco níveis diferentes de declividade, cujos valores foram: $0-3 \%$ (plano), 3-8\% (suave ondulado), 8$20 \%$ (ondulado), $20-45 \%$ (forte ondulado) e $45-$ $75 \%$ (montanhoso e escarpado).

No processo de definição das URHs (menu HRU Definition), optou-se por deixar o valor de $0 \%$ para o nível de sensibilidade nas três categorias apresentadas, pois essa indicação permite que todos os tipos de uso e ocupação do solo, tipos de solo e intervalos de declividade sejam considerados na modelagem, tornando o resultado mais preciso. Entretanto, o usuário pode definir níveis diferentes de zero para formação das URHs, porém ao limitar cada categoria (tipos de solo, uso do solo e declividade) o usuário perde informações que sejam inferiores ao limite escolhido, redistribuindo a área para categorias que estejam acima do limite definido. Caso fosse adotado um valor limite de $5 \%$ para esta pesquisa, alguns tipos de solo, uso do solo e declividades seriam desconsideradas na modelagem, pois estão abaixo de 5\% (Tabela 1 e 2).

Definidas as URHs insere-se os dados diários das variáveis meteorológicas (precipitação, temperatura, umidade relativa, radiação solar e velocidade do vento), assim como as médias mensais dessas variáveis (WXGEN). Caso o usuário não possua séries completas dos dados diários das variáveis climáticas, o SWAT fornece essas informações fazendo a simulação com seu próprio banco de dados (banco de dados dos Estados Unidos).

Para esta pesquisa, utilizou-se o banco de dados organizado para a região estudada com todas as variáveis climáticas trabalhadas pelo SWAT, assim como as médias mensais exigidas pelo gerador climático (WXGEN), obtidas por meio das estações citadas no item 2.3.3. Após a conclusão desta etapa, aplicaram-se os procedimentos para a modelagem inicial, ou seja, sem calibração, onde foi possível obter a primeira simulação da vazão para a área de estudo e a comparação com os dados observados.

Os resultados da modelagem inicial podem indicar que o modelo apresenta valores satisfatórios, dispensando o processo de calibração, no entanto, também pode indicar que a parametrização inicial (padrão do modelo) não é suficiente para modelar de forma aceitável a bacia (Santos et al., 2015).

\section{Resultados \\ Condições iniciais do processamento dos dados de entrada}

Dispondo das séries de precipitação, realizou-se uma análise de consistência para avaliar a homogeneidade das informações entre os postos pluviométricos. A Figura 6a-f apresenta a análise de consistência realizada para cada posto pluviométrico utilizado neste estudo, cujo objetivo foi de comprovar o grau de homogeneidade dos dados médios diários acumulados dos postos pluviométricos adotados. Observa-se que a declividade da reta (Figura 6a-f) mostra que os valores dos postos pluviométricos adotados para esta pesquisa são proporcionais aos valores médios acumulados dos postos da região. Dessa forma, os resultados mostram que não ocorreram inconsistências nos dados pluviométricos dos postos utilizados na modelagem.
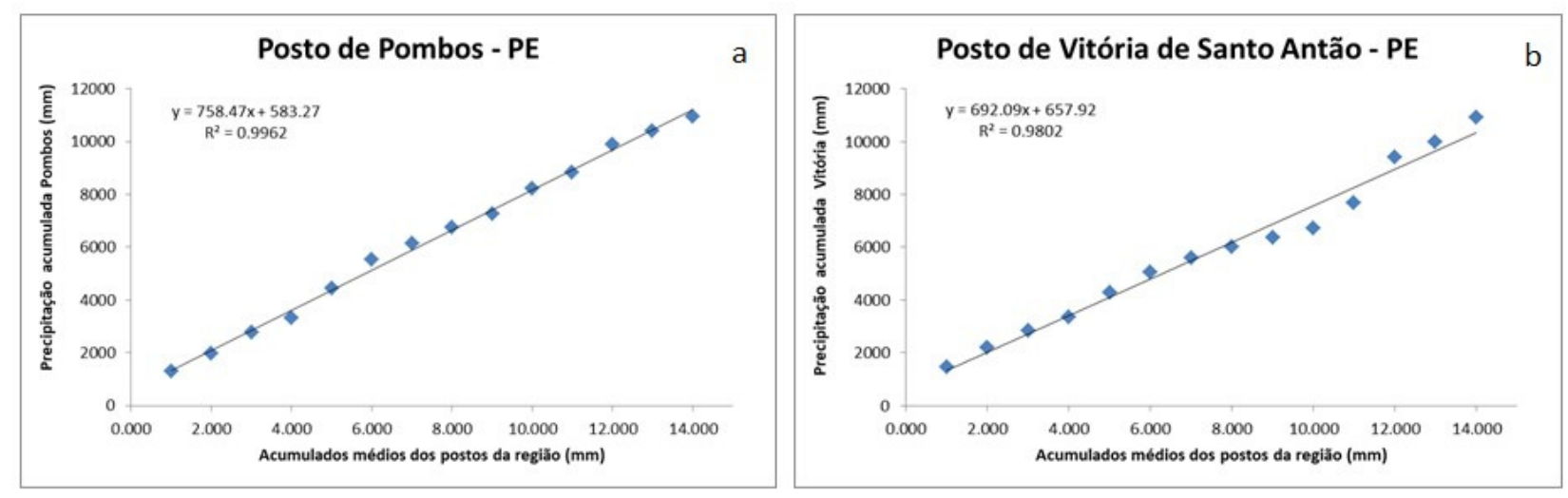

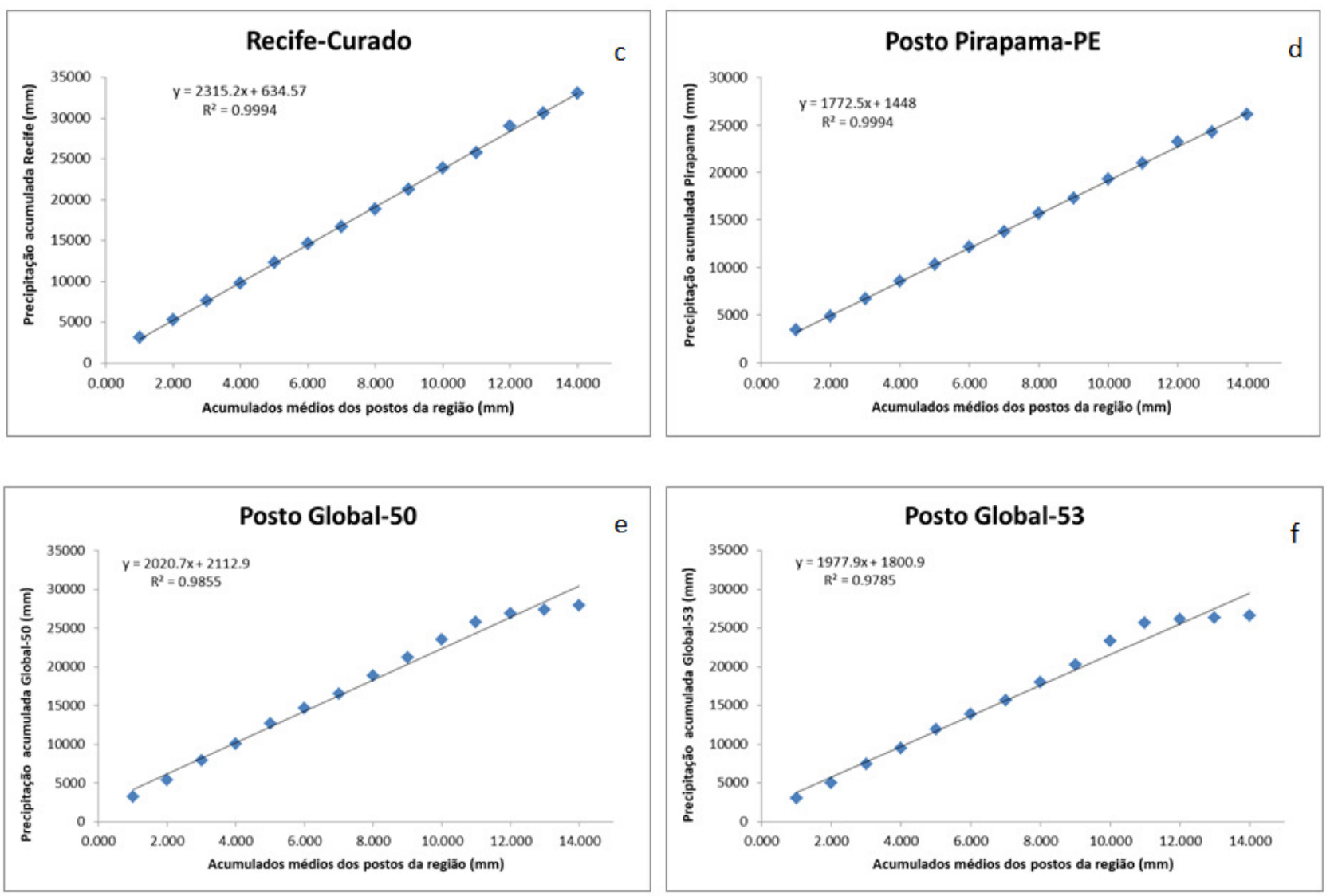

Figura 6. Análise de consistência dos dados pluviométricos utilizados na modelagem da Bacia do Rio Pirapama.

O delineamento automatizado baseado no MDE gerou 29 sub-bacias, com áreas variando entre 1,67 e 48,05 $\mathrm{km}^{2}$, cuja área acumulada adotada foi de 1210,23 hectares, indicada pelo próprio modelo, sem alteração manual. A Figura 7 ilustra a elevação na área da bacia e a divisão das sub-bacias geradas pelo ArcSWAT. O posto de observação dos dados fluviométricos está localizado na sub-bacia 11 e apresenta área de 8,16 $\mathrm{km}^{2}$. As elevações na área da bacia apresentaram variação de 1,78 a $552 \mathrm{~m}$, com elevações menores nas áreas próximas ao exutório da bacia e maiores na porção oeste, onde localiza-se a nascente do rio (Figura 7).

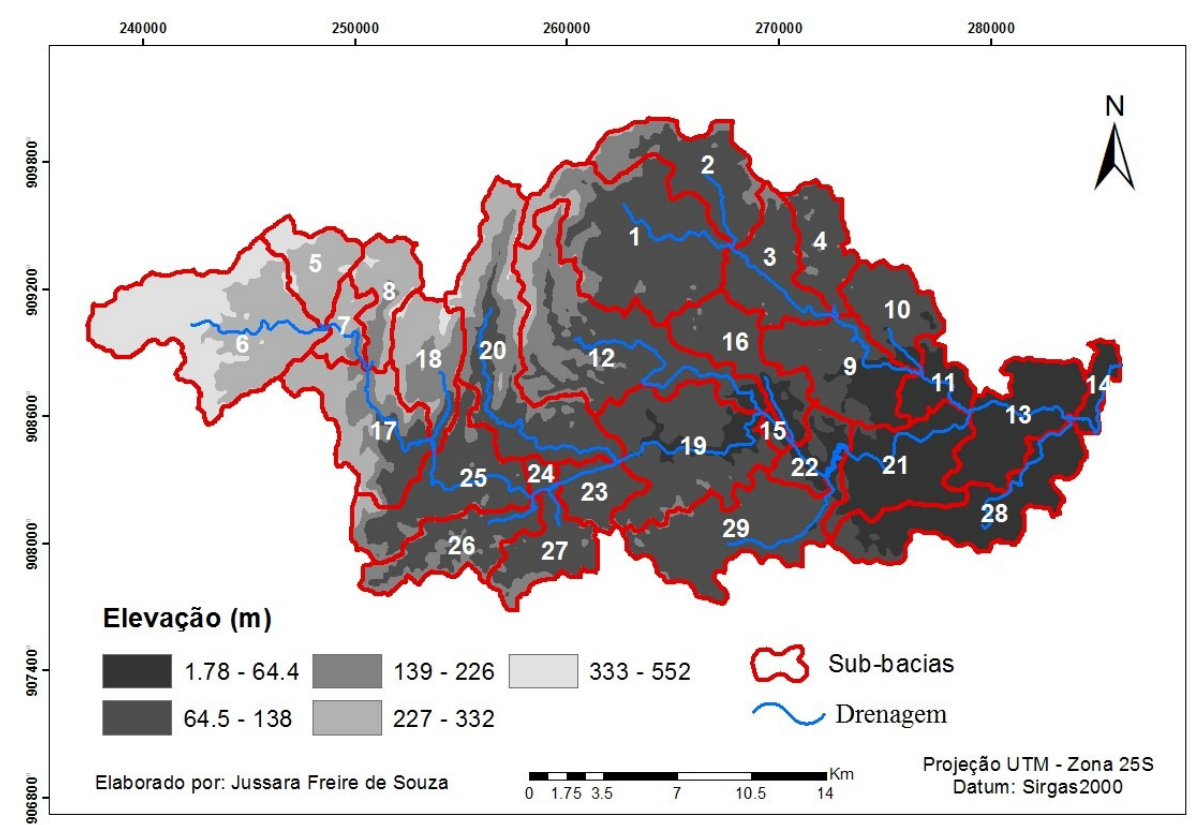

Figura 7. Elevação da área da Bacia do Rio Pirapama e as sub-bacias delimitadas pelo ArcSWAT. 
A partir da sobreposição dos mapas de tipos e uso do solo e das informações de declividade foram definidas as URHs para a bacia do Rio Pirapama. Esse processo resultou em 2138 Unidades de Respostas Hidrológicas, com definição do nível de sensibilidade de $0 \%$. O número de URHs geradas varia para cada bacia. As
URHs são definidas a partir de áreas homogêneas de uso e ocupação do solo, tipos de solo e declividade. Para este estudo as URHs derivaram da sobreposição de 6 tipos de uso e ocupação, 10 tipos de solo e 5 classes de declividade. A Tabela 4 apresenta a quantidade de URHs geradas para cada sub-bacia.

Tabela 4. Quantidade de URHs geradas em cada sub-bacia da Bacia do Rio Pirapama.

\begin{tabular}{cccc|cccc}
\hline Sub-bacia & Área $\left.\mathbf{( k m}^{2}\right)$ & Área $(\%)$ & URH & Sub-bacia & Área $\left(\mathbf{k m}^{2}\right)$ & Área $(\%)$ & URH \\
\hline 1 & 47,36 & 7,83 & 89 & 16 & 18,02 & 2,98 & 60 \\
2 & 23,20 & 3,83 & 86 & 17 & 26,78 & 4,43 & 121 \\
3 & 18,04 & 2,98 & 55 & 18 & 17,37 & 2,87 & 74 \\
4 & 12,79 & 2,11 & 40 & 19 & 36,61 & 6,05 & 99 \\
5 & 12,17 & 2,01 & 53 & 20 & 41,68 & 6,89 & 111 \\
6 & 48,05 & 7,94 & 81 & 21 & 24,09 & 3,98 & -63 \\
7 & 6,59 & 1,09 & 58 & 22 & 8,71 & 1,44 & 52 \\
8 & 12,23 & 2,02 & 70 & 23 & 9,63 & 1,59 & 82 \\
9 & 23,20 & 3,83 & 83 & 24 & 2,06 & 0,34 & 43 \\
10 & 14,79 & 2,44 & 58 & 25 & 26,84 & 4,44 & 109 \\
11 & 8,16 & 1,35 & 42 & 26 & 17,54 & 2,90 & 72 \\
12 & 46,48 & 7,68 & 102 & 27 & 14,20 & 2,35 & 70 \\
13 & 22,92 & 3,79 & 76 & 28 & 27,42 & 4,53 & 104 \\
14 & 4,84 & 0,80 & 37 & 29 & 31,68 & 5,24 & 90 \\
15 & 1,68 & 0,28 & 58 & - & - & - & - \\
\hline
\end{tabular}

Analisando a Tabela 4 é possível identificar que a sub-bacia 17 apresenta um maior número de URHs, porém não apresenta a maior área da bacia. Entretanto, essa sub-bacia apresentou uma maior diversidade de usos, tipos de solo e declividade, o que possivelmente gerou um maior número de combinações de URHs. Verificase ainda que as sub-bacias $12,20,25$ e 28 também apresentaram valores elevados de URHs, cujo motivo possivelmente está relacionado à maior diversidade de combinações entre os mapas sobrepostos. Por outro lado, as sub-bacias 4, 11, 14 e 24 apresentaram um menor número de URHs, por ter maior homogeneidade nos usos, tipos de solo e declividade, sobretudo nas informações de tipos de solo e declividade.

\section{Modelagem Inicial para a Bacia do Rio Pirapama}

A Figura 8 ilustra os resultados da simulação dos processos hidrológicos na Bacia do Rio Pirapama, obtidos por meio do modelo SWAT. Observa-se que a precipitação média da bacia para o período estudado foi de $1891,4 \mathrm{~mm}$, a evapotranspiração potencial foi de $1626,3 \mathrm{~mm}$, enquanto que a evapotranspiração real foi de 841 $\mathrm{mm}$.

A percolação para o aquífero raso foi de $573,83 \mathrm{~mm}$, o fluxo de retorno igual a $515,86 \mathrm{~mm}$, a ascensão capilar igual a $29,76 \mathrm{~mm}$ e a recarga para o aquífero profundo de $28,69 \mathrm{~mm}$. Para esta bacia o escoamento superficial simulado pelo SWAT foi de $284,89 \mathrm{~mm}$.

Os dados apresentados a seguir mostram os resultados iniciais da simulação da vazão sem calibração, para o posto fluviométrico adotado. A Figura 9 apresenta o hidrograma da vazão simulada e observada para o posto fluviométrico Destilaria Bom Jesus, para o período de 2000 a 2006 e a média precipitada em três postos pluviométricos próximos a bacia (Pirapama, Pombos e Vitória de Santo Antão).

Observa-se que a vazão simulada no posto da Destilaria Bom Jesus segue a tendência de variação da vazão observada, onde os valores simulados estão bem mais ajustados aos observados, visto algumas exceções, como em meados de 2004 a 2006, cujos resultados foram mais discrepantes em relação aos outros anos. Identifica-se que a maior parte dos dados foram subestimados pelo modelo, sobretudo nos picos mais elevados de vazão, como em meados dos anos 2000, 2002, 2004 e 2006, onde a subestimativa foi mais significativa (Figura 9). No que se refere à precipitação, a vazão observada representou melhor as máximas de chuva, exceto em meados de 2004 e 2005, onde a vazão não correspondeu muito bem às máximas de chuva. 


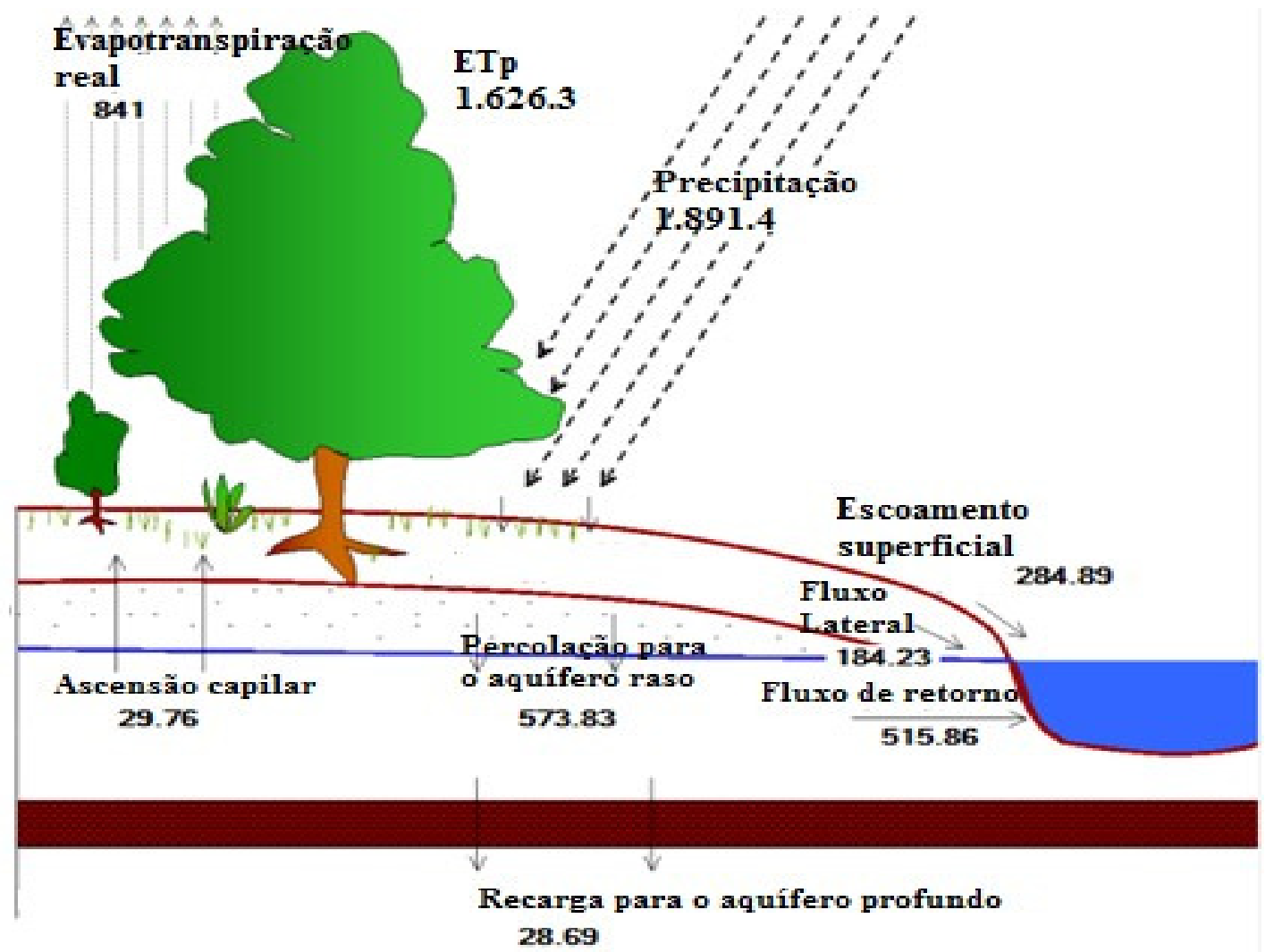

Figura 8. Processos hidrológicos simulados pelo modelo SWAT para a Bacia do Rio Pirapama.

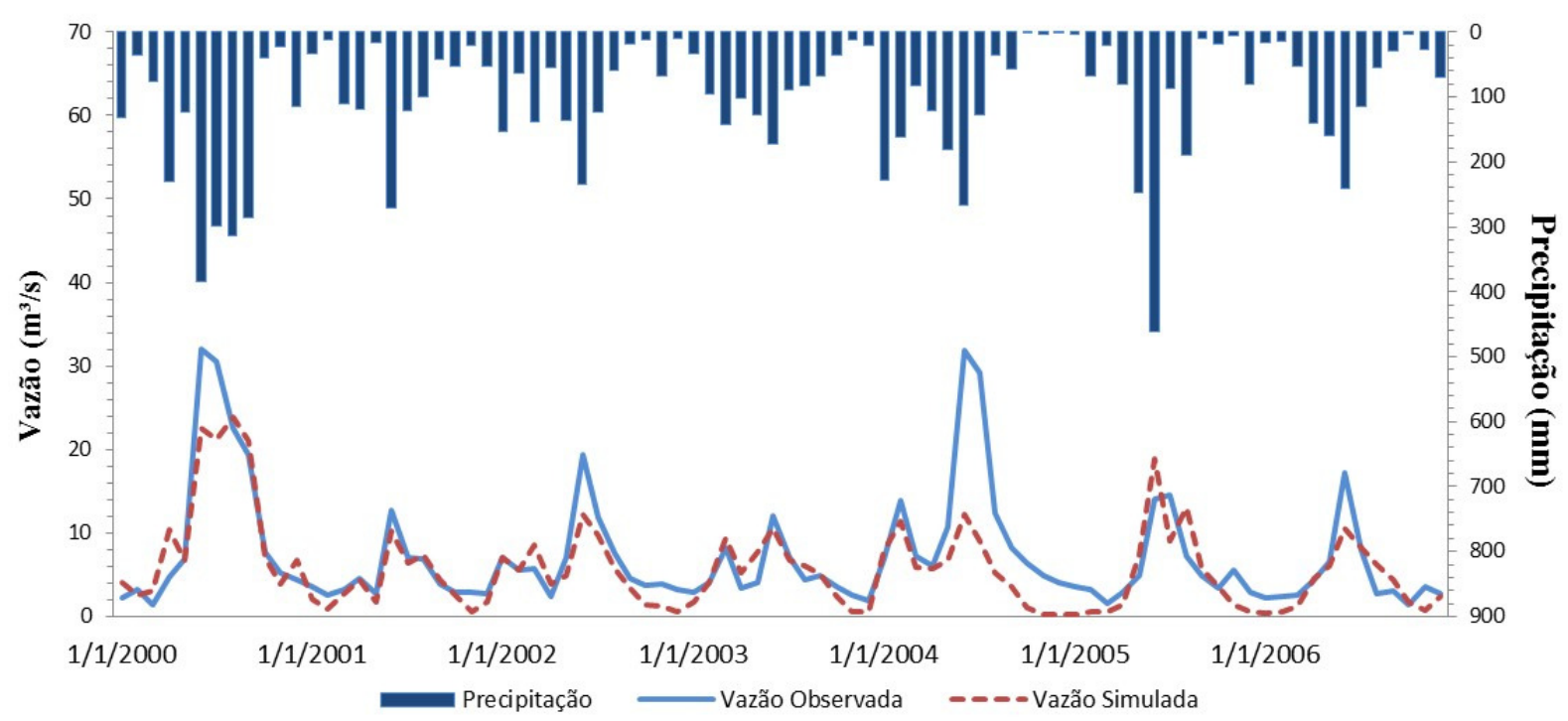

Figura 9. Relação entre as vazões $\left(\mathrm{m}^{3} \cdot \mathrm{s}^{-1}\right)$ observadas e simuladas para o posto da Destilaria Bom Jesus.

A Figura 10 mostra a comparação entre a vazão observada e simulada na modelagem com o SWAT para o Posto da Destilaria Bom Jesus (2000-2006). Na comparação entre a vazão simulada e observada do referido posto, observa-se uma desproporcionalidade em relação à distribuição dos dados. Parte dos valores mínimos da vazão observada é superestimada pelo modelo e parte subestimada, porém, no geral, os valores foram subestimados pelo modelo. Entretanto, o valor do $R^{2}(0,62)$ indica que há boa acurácia entre os dados da vazão observada e simulada pelo SWAT para esse posto.

A Tabela 5 mostra os dados estatísticos da comparação entre a vazão observada e a simulada pelo SWAT para o posto da Destilaria Bom Jesus. Verifica-se que a vazão observada apresenta uma diferença de $8,22 \mathrm{~m}^{3} \cdot \mathrm{s}^{-1}$ a mais que a vazão simulada pelo modelo, cujos valores máximos foram de $32,10 \quad \mathrm{~m}^{3} \cdot \mathrm{s}^{-1}$ e $23.88 \quad \mathrm{~m}^{3} \cdot \mathrm{s}^{-1}$, respectivamente. Nos valores mínimos a vazão observada também foi maior em relação à vazão simulada, com valores de 1,35 e $0,18 \mathrm{~m}^{3} \cdot \mathrm{s}^{-1}$, 
respectivamente, ou seja, uma subestimativa de $1,17 \mathrm{~m}^{3} \cdot \mathrm{s}^{-1}$. A média da vazão simulada em relação à observada foi subestimada em quase $80 \%$, cuja vazão média simulada foi de $5,73 \mathrm{~m}^{3} \cdot \mathrm{s}^{-1}$ e a vazão média observada de $7,19 \mathrm{~m}^{3} \cdot \mathrm{s}^{-1}$. Os valores do desvio padrão seguiram a tendência de subestimativa dos valores simulados pelo modelo SWAT (Tabela 5).

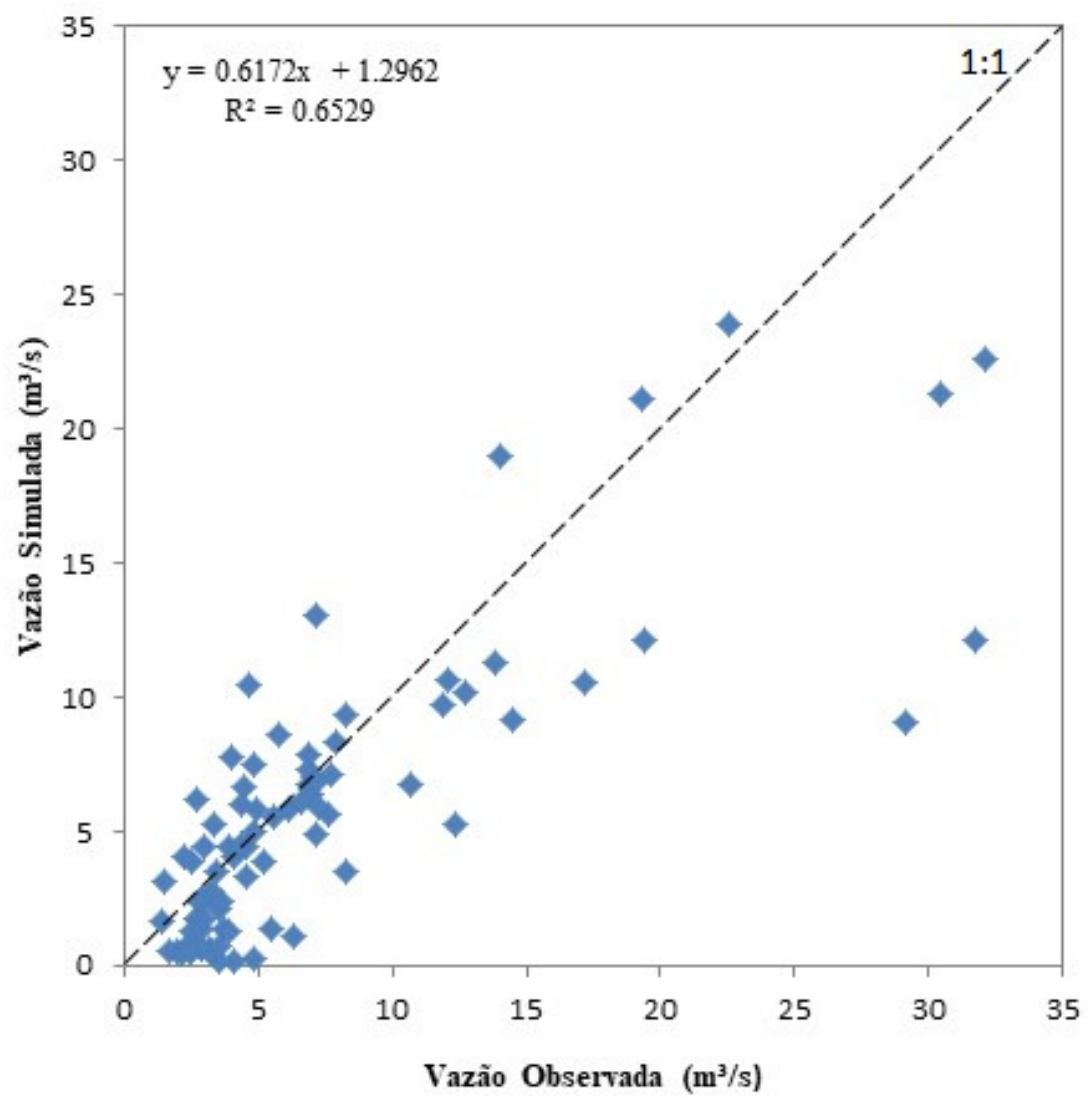

Figura 10. Comparação entre a vazão observada e simulada na modelagem inicial para o Posto da Destilaria Bom Jesus.

Tabela 5. Dados estatísticos da comparação entre a vazão observada e a simulada pelo modelo SWAT para o posto da Destilaria Bom Jesus.

\begin{tabular}{lcc}
\hline Estatística & Vazão Observada $\left(\mathbf{m}^{\mathbf{3}} \cdot \mathbf{s}^{\mathbf{1}}\right)$ & Vazão Simulada $\left(\mathbf{m}^{\mathbf{3}} \cdot \mathbf{s}^{\mathbf{- 1}}\right)$ \\
\hline Máxima & 32,10 & 23,88 \\
Mínima & 1,35 & 0,18 \\
Média & 7,19 & 5,73 \\
Desvio Padrão & 6,86 & 5,24 \\
\hline
\end{tabular}

\section{Discussão}

A análise de consistência mostrou que os dados de precipitação dos postos utilizados na modelagem apresentaram boa acurácia entre si. No entanto, de acordo com Paz (2004), embora à primeira vista os dados possam estar com valores supostamente coerentes, é possível haver inconsistência nas informações dos totais precipitados, oriundos de problemas como troca de operador, troca de equipamento, mudança nas condições vizinhas ao local onde o equipamento está instalado, etc. Segundo o método da Dupla Massa, o gráfico quando plotado com os dados de um determinado período de precipitação acumulada e dados de uma ou mais estações vizinhas deve resultar em uma linha reta. Essa análise corrobora com os resultados desta pesquisa. $\mathrm{O}$ processo de delineamento automatizado da bacia por meio do MDE definiu a quantidade de sub-bacias na área de estudo, assim como as áreas ocupadas por cada uma delas, cujas informações são utilizadas para a geração das URHs. A área da maior sub-bacia definida pelo modelo não ultrapassou os $49 \mathrm{~km}^{2}$. De acordo com Krysanova et al. (1998), cada área subdividida pelo modelo não deve ultrapassar $100 \mathrm{~km}^{2}$, visto que áreas maiores do que esse valor podem sofrer efeitos de escala, ou seja, diferentes usos e tipos de solo, 
alterações atmosféricas, diferenças na rede de drenagem, resultando em processos hidrológicos com comportamento distintos.

A geração das Unidades de Respostas Hidrológicas permitiu mostrar em cada sub-bacia todos os tipos de solo, uso do solo e declividade, pois adotou-se o nível de sensibilidade de $0 \%$, cuja intenção foi detalhar o máximo possível as características contidas nessas áreas. De acordo com Santos et al. (2015), a indicação de zero 0\% no nível de sensibilidade permite que todos os tipos de uso e ocupação e tipo de solo, bem como intervalos de declive, sejam considerados na criação das URHs. Castro (2013) obteve 628 URHs geradas pelo modelo SWAT na bacia experimental do alto rio Jardim, no Distrito Federal.

\section{Modelagem Inicial para a Bacia do Rio Pirapama}

Na modelagem com o SWAT são obtidos diversos resultados que simulam o comportamento das variáveis hidrológicas ao longo do tempo. Os resultados incluem informações de precipitação, evapotranspiração, escoamento superficial, fluxo de base, ascensão capilar, percolação para o aquífero raso, recarga do aquífero profundo, informações sobre uso do solo, pesticidas, qualidade da água, nutrientes, entre outros.

Por meio dos resultados apresentados, pode-se inferir que parte da precipitação que ocorre na bacia, quase $50 \%$, retorna para a atmosfera por evapotranspiração (ETr), ou seja, pela evaporação do solo e transpiração das plantas. No entanto, identifica-se que o valor da evapotranspiração potencial encontra-se bastante elevado, sendo necessário melhores ajustes na modelagem do balanço hídrico.

$\mathrm{Na}$ simulação inicial, sem o processo de calibração, percebe-se que o modelo representa bem a sazonalidade, mesmo com algumas superestimativas quanto ao volume de escoamento comparado aos valores observados, assim como representa bem a redução da vazão, porém não representa bem o pico da vazão. No que se refere ao resultado do $\mathrm{R}^{2}$, os valores simulados indicaram boa acurácia em relação aos dados observados, mesmo havendo subestimativa de grande parte dos dados.

Colombo et al. (2016) realizaram uma análise prévia dos resultados através da simulação inicial (sem calibração) para verificar a concordância entre os dados simulados e medidos da variável vazão em uma bacia hidrográfica no Sul de Santa Catarina, Brasil. A análise mostrou que na maior parte do período analisado, a vazão simulada foi superestimada em relação aos dados medidos, exceto em dois meses da série, em que a vazão foi subestimada. O modelo apresentou um ajuste aceitável dos dados mensais de vazão, cujo $\mathrm{R}^{2}$ foi de 0,89. Apesar dos valores obtidos terem sido considerados aceitáveis, os autores indicam aplicar a calibração do modelo para tentar ajustar melhor a vazão simulada em relação à observada, sobretudo nos valores de pico.

A análise desta pesquisa também pode ser comparada aos encontrados por Santos et al. (2013), que utilizaram o modelo SWAT para analisar o escoamento superficial da Bacia do Rio Tapacurá em Pernambuco, para o período de 1997 a 2004. Os resultados desse estudo mostraram que, na fase de simulação, o modelo superestimou a vazão da área de estudo, no entanto apresentou $\mathrm{R}^{2}$ de 0,73 , considerado bom quando comparado aos dados observados. Após a fase de calibração houve um ajuste considerável da vazão calculada pelo modelo com a vazão observada, cujo $\mathrm{R}^{2}$ aumentou para 0,90 .

Dessa forma, infere-se que o comportamento das vazões mostrada nas Figuras 9 e 10, obtidas a partir da modelagem inicial, é um indicativo de que o modelo poderá ser calibrado em estudos futuros, apesar de apresentar boa correlação e baixa discrepância entre os dados. Esses valores são aceitáveis conforme Moriasi et al. (2007), que analisaram diversos métodos estatísticos para verificar o comportamento dos modelos de simulação para bacias hidrográficas, considerando assim, como satisfatório para valores de $\mathrm{R}^{2}<0,70$ (Bonumá et al., 2013). A calibração do modelo poderá ajustar os valores da vazão simulada aos da vazão observada, cujo objetivo é representar os dados observados de maneira mais satisfatória

\section{Conclusão}

De acordo com as informações geradas, o modelo subestimou a maior parte dos dados de vazão no posto Destilaria Bom Jesus, no entanto apresentou dados simulados relativamente bem ajustados aos valores observados, quando se considera que os mesmos não foram calibrados.

Dessa forma, entende-se que possivelmente após o processo de calibração os dados estimados podem melhorar em relação aos observados, uma vez que o modelo parece representar adequadamente os processos hidrológicos na bacia. Em estudos futuros serão aplicados o processo de calibração e validação do modelo SWAT na Bacia Hidrográfica do Rio Pirapama. Após a calibração e validação o modelo pode ser usado para cenários de previsão de impactos de mudanças climáticas e de alterações de uso do solo. 


\section{Agradecimentos}

Os autores agradecem a Fundação de Amparo a Ciência e Tecnologia de Pernambuco (FACEPE) pela bolsa de doutorado da primeira autora, ao projeto SUPER financiado pelo CNPq (Proc. 446254/2015) e ao Projeto dp Edital Universal do CNPq (Proc. 448236/2014-1) pela bolsa PQ (Produtividade e Pesquisa) da segunda autora.

\section{Referências}

Al-DOUSARI, A.; MILEWSKI, A.; DIN, S. U.; AHMED, M. 2010. Remote Sensing Inputs to SWAT Model for Groundwater Recharge Estimates in Kuwait. Advances in Natural and Applied Sciences, v. 4, n. 1, p. 71-77.

ANDRADE, C. W. L.; MONTENEGRO, S. M. G. L.; LIMA, J. R. S.; MAGALHÃES, A. G.; SRINIVASAN, R. 2016. Modelagem Hidrológica de uma sub-bacia do Alto Mundaú utilizando o modelo SWAT. XII Simpósio de Recursos Hídricos do Nordeste-ABRH, Aracajú, SE, Brasil, ABRH. pp. 01-10.

ARNOLD, J. G.; SRINIVASAN, R. MUTTIAH, R. S. WILLIAMS, J. R. 1998. Large area hydrologic modeling and assessment part I: Model development. Journal of the American Water Resources Association, v. 34, n. 1, p. 1-17.

ARAGÃO, R.; CRUZ, M. A. S.; AMORIM, J. R. A.; MENDONÇA, L. C.; FIGUEIREDO, E. E.; SRINIVASAN, V. S. 2013. Análise de sensibilidade dos parâmetros do modelo SWAT e simulação dos processos hidrossedimentológicos em uma bacia no agreste nordestino. Revista Brasileira de Ciências do Solo, v. 37, n. 4, p. 10911102.

ARNOLD, J. G.; MORIASI, D. N.; GASSMAN, P. W.; ABBASPOUR, K. C.; WHITE, M. J.; SRINIVASAN, R.; SANTHI, C.; HARMEL, R. D.; VAN GRIENSVEN, A.; VAN LIEW, M. W.; KANNAN, N.; JHA, M. K. SWAT: Model Use, Calibration, and Validation. 2012. American Society of Agricultural and Biological Engineers, Transactions of the ASABE, v. 55, n. 4, p. 14911508 .

BALDISSERA, G. C. 2005. Aplicabilidade do modelo de simulação hidrológica SWAT (Soil and Water Assessment Tool), para a Bacia Hidrográfica do Rio Cuiabá/MT. 132f. Dissertação de Mestrado em Física e Meio Ambiente, Universidade Federal do Mato Grosso, Cuiabá, Mato Grosso, Brasil, 132p.
BATISTA, W. R. M.; NETO, A. O. A.; SILVA, B. B.; SOUSA, A. I. F.; VASCO, A. N. 2013. Determinação do balanço de radiação com auxílio de imagens orbitais na Bacia Hidrográfica do Rio Jacaré, Sergipe. Scientia Plena, v. 9, n. 4, p. 01-10.

BORGES, A. A. S. 2013. Educação ambiental e fortalecimento da ação participativa para gestão da Bacia do Rio Araguari-MG. 209f. Tese de Doutorado em Geografia e Gestão do Território, Universidade Federal de Uberlândia, Uberlândia, Minas Gerais, Brasil, 209p.

BONUMÁ, N. B.; CORSEUIL, C. W.; KOBYIAMA M.; ZANIN, P. R.; CORREA, F. 2013. Estimativa do balanço hídrico de uma bacia hidrográfica com o modelo SWAT. Anais XX Simpósio Brasileiro de Recursos Hídricos, Bento Gonçalves, RS, Brasil, ABRH.

BRESSIANI, D. A.; GASSMAN, P. W.; FERNANDES, J. G.; GARBOSSA, L. H. P.; SRINIVASAN, R.; BONUMÁ, N. B.; MENDIONDO, E. M. 2015. Review of Soil and Water Assessment Tool (SWAT) applications in Brazil: Challenges and prospects. Int. J. Agric. \& Biol. Eng., v. 8, n. 3, p. 9-35.

CASTRO, K. B. 2013. Avaliação do modelo SWAT na simulação da vazão em bacia agrícola do cerrado intensamente monitorada. Dissertação de Mestrado em Geociências, Universidade de Brasília, Brasília, Brasil, 141p.

COLOMBO, T. C.; CORSEUIL, C. W.; BACK, A. J.; MAMEDIO, F. M. P.; SEHNEM, M.; BELLETTINI, A. 2016. Estimativa de vazão de uma Bacia Hidrográfica do Sul de Santa Catarina com modelagem distribuída. Anais V Simpósio de Integração Tecnológica do Sul Catarinense, Araranguá. Disponível em: http://labhidrogeo.paginas.ufsc.br/files/2016/08/A rtigo-SICT.pdf. Acessado em 22/02/2017.

CPRH/DFID. 1998. Estudo dos recursos hídricos da bacia do rio Pirapama. Recife: Companhia Pernambucana de Meio Ambiente/Department for International Development.

CPRH. Companhia Pernambucana de Meio Ambiente. 2003. Diagnóstico Socioambiental do Litoral Sul de Pernambuco. Recife.

CPRH. Companhia Pernambucana de Meio Ambiente. 2004. Laudos de qualidade da água do monitoramento da barragem do Rio Pirapama. Recife. 
EMBRAPA. Empresa Brasileira de Agropecuária. 2000. Levantamento de reconhecimento de baixa e média intensidade dos solos do Estado de Pernambuco. Boletim de Pesquisa n.11. Rio de Janeiro: Embrapa Solos. 378p.

EMBRAPA. Empresa Brasileira de Agropecuária. 2002. Zoneamento agroecológico do Estado de Pernambuco. Recife: Embrapa Solos UEP Recife/SPRRA-PE.

FALCÃO NETO, J. M. 2002. Modelagem matemática da hidrodinâmica e da qualidade da água do trecho a jusante da barragem do rio Pirapama. Dissertação de Mestrado em Oceanografia, Universidade Federal de Pernambuco, Recife, Pernambuco, 174p.

FERNANDES, J. G. 2015. Estimativa de vazão e produção de sedimentos na Bacia Hidrográfica do Rio São Francisco, utilizando o modelo SWAT. Tese de Doutorado em Geografia, Universidade Federal de Pernambuco, Recife, Pernambuco, Brasil, 185p.

GAMA, A. M. F. 2001. Pirapama: Criando o Desenvolvimento Sustentável Local. Uma experiência que vale a pena conhecer e repetir. Recife: CPRH/DFID, 59p.

GOMES, C. M. S. 2004. Água: recurso desencadeador de conflitos? Os impactos sociais da construção da Barragem de Pirapama. Dissertação de Mestrado em Serviço Social, Universidade Federal de Pernambuco, Recife, Pernambuco, Brasil, 84p.

GOMES, C. M. S. 2012. Na trilha da ecologia política: a construção da barragem de Pirapama e a Associação Vanguarda Ecológica no município do Cabo de Santo Agostinho. Tese de Doutorado em Serviço Social, Universidade Federal de Pernambuco, Recife, Pernambuco, Brasil, 252p.

HIDALGO, P. 1995. Apostilas diversas de metodologia de planejamento ambiental: curso sobre planejamento ambiental participativo em bacias hidrográficas. Florianópolis: UFSC.

IBGE. Instituto Brasileiro de Geografia e Estatística. 2007. Manual Técnico de Pedologia. Manuais Técnicos em Geociências. Ministério do Planejamento, Orçamento e Gestão. 2 ed., Rio de Janeiro: IBGE.

IBGE. Instituto Brasileiro de Geografia e Estatística. Censo Demográfico 2010. 2010.
Disponível

em:

http://www.ibge.gov.br/home/estatistica/populaca o/censo2010/sinopse/sinopse_tab_rm_zip.shtm.

Acessado em: 27/10/2016.

KLEMES, V. 1986. Operational testing of hydrological simulation. Hydrological Sciences Journal, v. 31, p. 13-24.

KRYSANOVA, V., MÜLLER-WOHLFEIL, D.I. E BECKER, A. 1998. Development and test of a spatially distributed hydrological/water quality model for mesoscale watersheds. Ecological Modelling, v. 106, n. 2, p. 261-289.

LELIS, T. A.; CALIJURI, M.L.; FONSECA, A.S.; LIMA, D.C.; ROCHA, E.O. 2012. Análise de sensibilidade e calibração do modelo SWAT aplicado em Bacia Hidrográfica da Região Sudeste do Brasil. Revista Brasileira de Ciência do Solo, v. 36, p. 623-634.

MERCURI, E. G. F.; DEPPE, F.; LOHMANN, M.; SIMÕES, K. 2009. Metodologia da geração de dados de entrada e aplicação do modelo SWAT para bacias hidrográficas brasileiras. Anais XIV Simpósio Brasileiro de Sensoriamento Remoto. Natal, RN, Brasil, pp. 4773-4780.

MIRANDA, E. E. (Coord.). 2005. Brasil em Relevo. Campinas: Embrapa Monitoramento por Satélite. Disponível em: http://www.relevobr.cnpm.embrapa.br. Acesso em: 18 Maio 2017.

MORIASI, D. N.; ARNOLD, J. G.; VAN LIEW, M.W.; BINGNER, R. L.; HARMEL, R. D.; VEITH, T. L. 2007. Model evaluation guidelines for systematic quantification of accuracy in watershed simulations. American Society of Agricultural and Biological Engineers, v.50, n.3, p. 885-900.

NEITSCH, S. L; ARNOLD, J. G; WILLIAMS, J. R. 2005. Soil and water assessment tool. Input/output file documentation: Version. Temple: Blackland Research Center, Texas Agricultural Experiment Station, EUA, 530p.

NEITSCH, S. L.; ARNOLD, J. G.; KINIRY, J. R.; WILLIANS GRASSLAND, J. R. 2011. Soil and Water Research Laboratory. Soil and Water Assessment Tool Theoretical Documentation Version 2009. Agricultural Research Service Blackland Research Center-Texas Agrilife Research. Texas A\&M University System, 2011. 
NÓBREGA, R. S.; SOUZA, E. P. ; SOUZA, F. A. S. 2008. Análise da utilização de dados do satélite TRMM em um modelo hidrológico semidistribuído na bacia do rio Jamari (RO). Revista Brasileira de Geografia Física, v. 1, p. 4960.

PAGLIERO, L.; BOURAOUI, F.; WILLEMS, P.; DIELS, J. 2014. Large-scale hydrological simulations using the soil water assessment tool, protocol development and application in the Danube Basin. Journal of Environmental Quality. Disponível em: https://dl.sciencesocieties.org/publications/jeq/pdf s/43/1/145. Acesso em: 13/08/2015.

PAZ, A. R. 2004. Apostila de Hidrologia Aplicada. Universidade Estadual do Rio Grande do Sul. Caxias do Sul, 138p.

RENNÓ, C. D.; SOARES, J. V. 2003. Uso do índice topográfico como estimador da profundidade do lençol freático. Anais XI Simpósio Brasileiro de Sensoriamento Remoto. Belo Horizonte, MG, Brasil.

SANTOS, L. L. 2009. Modelos HidráulicosHidrológicos: Conceitos e Aplicações. Revista Brasileira de Geografia Física, v. 2, n. 3, p. 1-19.

SANTOS, J. Y. G.; CARVALHO NETO, J. G.; SILVA, R. M.; MONTENEGRO, S. M. G. L.; SANTOS, C. A. G. 2013. Aplicação do modelo SWAT para a simulação chuva-vazão na Bacia do Rio Tapacurá, Estado de Pernambuco. Anais Simpósio Brasileiro de Recursos Hídricos. Bento Gonçalves. RS, Brasil, pp.01-08.

SANTOS, J. Y. G.; SILVA, R. M.; CARVALHO NETO, J. G.; MONTENEGRO, S. M. G. L.; SANTOS, C. A. G.; SILVA, A. M. 2015. Land cover and climate change effects on streamflow and sediment yield: a case study of Tapacurá River basin, Brazil. Proceedings of the International Association of Hydrological Sciences, v. 371, p. 189-193.
SECTMA. Secretaria de Ciência, Tecnologia e Meio Ambiente. 1998. Recife: Plano Estadual de Recursos Hídricos do Estado de Pernambuco, v. 13, 849p.

SETTI, A. A.; LIMA, J. E. F.; CHAVES, A. G. M.; PEREIRA, I. C. 2001. Introdução ao Gerenciamento de Recursos Hídricos. Brasília: Agência Nacional da Água, 225p.

SILVA, R. M.; SANTOS, C. A. G. 2005. Aplicação do modelo distribuído açumod na modelagem das potencialidades das sub-bacias do rio Pirapama. Anais XVI Simpósio Brasileiro de Recursos Hídricos. João Pessoa, PB, Brasil.

SILVA, C. A. I. 2014. Análise de aplicabilidade da interface do modelo hidrológico SWAT-SIG no estudo da produção de sedimentos em uma bacia no Nordeste do Brasil. Dissertação de Mestrado em Recursos Hídricos e Saneamento, Universidade Federal de Alagoas, Alagoas, Brasil, 53p.

SOUSA, A. M. L.; VITORINO, M. I.; CASTRO, N. M. R.; BOTELHO, M. N.; SOUZA, P. J. O. P. 2015. Evapotranspiration from Remote Sensing to Improve the Swat Model in Eastern Amazônia. Floresta e Ambiente. ISSN 2179-8087 (online), ISSN 1415-0980 (impresso).

SHARPLEY, A. N.; WILLIANS, J. R. 1990. EPIC - Erosion productivity impact calculator: Model Documentation. Washington: U.S: Department of Agriculture, 145p.

SRINIVASAN, V. S.; PAIVA, F. M. L. 2009. Regional validity of the parameters of a distributed runoff-erosion model in the semi-arid region of Brazil. Science in China Series E: Technological Sciences, v. 52, n. 11, p. 3348-3356.

STRETTA, C. 2000. Hydrodynamic Modelling of the Pirapama Estuarine System after upstream regulation. Rapport INPT/ENSEEIHT.

TUCCI, C. E. M.; BELTRAME, L. F. S. 2014. Evaporação e evapotranspiração. In: TUCCI, C. E. M. (Org) Hidrologia: ciência e aplicação. Editora da UFRS: Porto Alegre, Cap. 7, p.253-288. 